\title{
Interdiscursividade: literatura nas charges em tempos de pandemia
}

\section{Interdiscursivity: literature on charges in pandemic times}

\author{
Luciane Silva de Souza $^{1 *}$, Claitonei de Siqueira Santos ${ }^{2}$
}

\begin{abstract}
RESUMO
Este artigo objetiva analisar o interdiscurso como elemento basilar na constituição dos sentidos nas charges. Para tanto, pretendemos discutir como a interdiscursividade entre os enunciados contribui para que os sentidos sejam produzidos com respaldo na Análise do Discurso de linha francesa. Nesse viés, buscamos Michel Pêcheux e Michel Foucault. Embora os estudiosos tenham pontos divergentes, traremos algumas concepções em que são convergentes. A análise realizada se deu a partir da pesquisa bibliográfica, cujo foco foi apresentar conceitos que subsidiam o tema aqui tratado, em um primeiro momento; e, em um segundo momento, organizamos e selecionamos charges do período compreendido entre o mês de março e dezembro de 2020, ano de Pandemia COVID-19, para compor nosso corpus, Ao analisar as charges selecionadas, buscamos os discursos veiculados pela mídia, que permitiram a construção dos sentidos e como os enunciados dialogam nesta constituição do discurso chargístico, buscando na memória, elementos do texto literário, os quais lhe servem de referência.
\end{abstract}

Palavras-chave: Análise do Discurso; Charge; COVID-19; Interdiscurso; Literatura;

\begin{abstract}
This article aims to analyze the interdiscourse as a basic element in the constitution of meanings in cartoons. In order to do so, we intend to discuss how the interdiscursivity between the utterances contributes to the production of meanings based on the French Discourse Analysis. In this bias, we look for Michel Pêcheux and Michel Foucault. Although scholars have divergent points, we will bring some conceptions in which they are convergent. The analysis carried out was based on the bibliographic research, whose focus was to present concepts that support the theme discussed here, at first; and, in a second moment, we organized and selected cartoons from the period between March and December 2020, the year of the COVID-19 Pandemic, to compose our corpus. allowed the construction of meanings and how the utterances dialogue in this constitution of the cartoon speech, searching in memory, elements of the literary text, which serve as a reference.
\end{abstract}

Keywords: Speech analysis; Cartoon; COVID-19; Interdiscourse; Literature;

\footnotetext{
${ }^{1}$ Rede Municipal de Educação de Goiânia-GO. Centro Universitário Facunicamps.

*E-mail: profalucianesouza@gmail.com

${ }^{2}$ Universidade Federal de Goiás/GO. Centro Universitário FacUnicamps.
} 


\section{INTRODUÇÃO: DIÁLOGOS INICIAIS}

O presente texto visa analisar as charges selecionadas tendo como subsídio a concepção de discurso e interdiscurso, formação discursiva e, ainda, retoma o conceito de memória e acontecimento. Para isso, recorremos à Análise do Discurso francesa, doravante $\mathrm{AD}$, considerando as discussões de Michel Pêcheux e os pontos convergentes deste teórico com Michel Foucault. Importa afirmar que a charge, enquanto gênero do discurso, reúne textos e/ou discursos diversos que são veiculados pela mídia constituindo os efeitos de sentido. Isso porque o discurso surge sempre a partir do diálogo com outros textos e, por isso, a interdiscursividade se torna elemento central na nossa análise.

Os textos chargísticos colaboram tanto para constituir, como para legitimar sentidos e isso ocorre porque, ao utilizar os recursos verbais e não-verbais de que dispõe, a charge possibilita uma interpretação que foge à superfície do texto em si e per si e dá margem para a construção de novos significados. Para Pilla e De Quadros (2009, p. 227), “Todo processo de elaboração de charges tem por base ou fonte de inspiração outros textos e discursos, por jornais impressos e outros meios de comunicação. (...) o discurso da charge desvela o cotidiano da sociedade...”. Sendo assim, é necessário conhecer o momento em que a relação entre os interlocutores e o discurso ocorre, em especial, e até, particularmente, a crítica que recai sobre os fatos políticos e os protagonistas das charges, sem os quais não se constrói os efeitos de sentido a partir do conceito de interdiscurso. Por esta razão, nosso interesse aqui é como a charge produz ou pode produzir sentidos. Segundo Silva (2012, p. 307), é preciso “(...) a charge ser tecida a partir de outros textos e/ou discursos, especialmente notícias veiculadas na mídia impressa e televisiva, atualizando discursos que circulam na sociedade contemporânea”.

Dessa forma, o ponto de partida do nosso texto é compreender que cada texto surge em constante diálogo com outros textos. Além disso, como Foucault assevera, todo enunciado pressupõe outros enunciados anteriores a ele e o interdiscurso nada mais é que a existência de diversos discursos de momentos históricos e lugares sociais, também, diversos que se "entrecruzam no interior de uma formação discursiva" (SILVA, 2012, p. 310). Por esta razão, podemos afirmar que todo enunciado é "heterogêneo e carregado de conhecimento linguístico, histórico, social e ideológico" (SILVA, 2012, p. 310).

Nossa proposta, então, é analisar o interdiscurso como elemento fundamental na constituição dos sentidos nas charges. Para isso, buscamos subsídios teóricos por meio da pesquisa bibliográfica, que discutissem os conceitos de discurso, interdiscurso e formação 
discursiva, além é claro, de memória e acontecimento a partir de Pêcheux (1983, 1990). Foucault (1996, 2002, 2008, 2015), Gregolin (2005), Brandão (2004), Mussalin (2004), Possenti (2006), Orlandi (1991, 2005, 2012), além de outros. Ainda, realizamos o levantamento e seleção das charges que poderiam compor o corpus para análise tendo como critério a relação com a literatura infantil e/ou infantojuvenil.

\section{SUBSÍDIOS TÉORICOS}

A Análise do Discurso, AD, tem como objetivo compreender como o objeto simbólico produz sentido, "como ele está investido de significância para e por sujeitos", ou seja, busca observar as condições que permite o aparecimento do discurso e porque torna-se um determinado sentido e não outro, nunca deixando de relacionar o linguístico, o histórico e o ideológico (ORLANDI, 2005).

Para Pêcheux, o discurso é considerado como efeito de sentido entre os interlocutores e é marcado pelos já-ditos, relacionado a um sujeito que diz e se diz por meio dele. E, portanto, uma prática social que se produz materialmente pela língua e só pode ser entendida por meio de uma retomada do conceito de formação discursiva, FD. Pêcheux, assim como Foucault, compreende que não existe um sujeito 'original', mas um sujeito que é disperso e os discursos são práticas que formam sistematicamente os objetos de que falam, os quais modificam os domínios aos quais pertencem.

Ninguém tem o direito de dizer tudo como quer ou a qualquer momento ou mesmo acerca de qualquer coisa, pois há regras de formação que governam os nossos discursos. Conforme o autor, o discurso é o resultado do embate entre os sujeitos e os saberes; é o sentido e o reconhecimento deste que irão permitir se produzir no e por meio do discurso.

Embora haja algumas semelhanças entre as discussões propostas por Pêcheux e Foucault, também há inúmeros pontos que eles divergem. Enquanto para Pêcheux, o discurso necessita ser pensado e, em consequência, o sujeito também, levando-se em conta a ideologia e o inconsciente, na visão lacaniana, em especial, na segunda fase de suas discussões; Foucault vê o discurso permeado pela dinâmica entre o desejo e o poder. Nesse viés, é possível entendermos porque ele se ocupa com obediência aos processos de regulação do discurso visto que para este estudioso, o discurso vive a exclusão e sofre interdições. E, complementa que a produção do discurso em uma sociedade é "redistribuída por certo número de procedimentos que têm por função conjurar seus 
poderes e perigos, dominar seu acontecimento aleatório, esquivar sua parada e temível materialidade" (FOUCAULT, 2015, p. 27)

Segundo Foucault, o discurso é um conjunto de enunciados que se apoia na mesma formação discursiva sendo constituído por um número limitado de enunciados, para os quais podemos definir um conjunto de condições de existência. (FOUCAULT, 2002, p. 135). Já em Pêcheux, percebemos que o seu primeiro e segundo momentos ou fases foram permeados (as) pelo conceito de discurso como efeito de sentido entre os interlocutores, enquanto no terceiro momento, a partir da década de 1980, com a publicação de Discurso: estrutura ou acontecimento, o discurso é definido como sendo da ordem da estrutura e do acontecimento (PÊCHEUX, 2006). Para o autor, "todo discurso marca a possibilidade de uma desestruturação - reestruturação dessas redes e trajetos, todo discurso é um índice potencial de uma agitação nas filiações sócio-históricas de identificação..." (PÊCHEUX, 2006, p. 56, grifos nossos).

Pêcheux, à medida que se aproxima da noção de acontecimento "apresenta um reencontro com a memória, considerando que os corpos sócio-históricos dos traços discursivos constituem o espaço de memória, assimilando-o ao interdiscurso" (SARGENTINI, 2006, p. 187). E seu texto, Lecture et mémoire: Project de recherche, se refere à "importância da inscrição das discursividades no acontecimento".

Para Pêcheux, o acontecimento é uma imersão do novo no discurso, isto é, uma mudança, um acontecimento, ressignificação. O acontecimento é um princípio de organização, pois pode ser observado tanto no contexto atual, quanto na memória que retoma ao surgir. Assim, na realidade, é a memória que será reorganizada por meio do acontecimento. Com isso, é a repetição que faz com que o enunciado se junte ao acontecimento, cuja responsabilidade é fazer surgir um enunciado de outro, produzindo novos ecos. De acordo com Pêcheux (1983), “todo enunciado é intrinsecamente ligado para derivar para um outro", pois o sentido, na $\mathrm{AD}$, não é entendido a partir de uma estrutura fixa, posto que é histórico, assim podendo ocasionar outro discurso. Possenti (2006, p. 93) afirma que, “A noção de acontecimento é fundamental para a AD por sua relação com a enunciação que, quase naturalmente, é concebida como um evento, e até um evento que não se repete e por sua relação com a história, campo para o qual a noção de acontecimento é uma espécie de matéria prima".

Interessa notar, ainda, que os discursos surgem das experiências, das relações com outros discursos. Neste aspecto, Pêcheux compreende o sentido como historicamente 
determinado e não dados anteriormente na materialidade linguística, mas se constitui por meio da relação entre sujeito, história e linguagem. Por isso, o discurso se origina de situações impregnadas de formações discursivas e formações ideológicas. Estas formações discursivas e formações ideológicas é que determinarão o posicionamento dos sujeitos em relação ao que deve/pode ser dito e ao que não deve ser dito em um determinado momento. São estas condições de produção que se se ligam diretamente à instancia verbal de produção do discurso, ao contexto sócio-histórico, aos interlocutores, ao lugar de fala, e a imagem que estes interlocutores fazem de si e do outro (BRANDÃO, 2004, p. 105). Dessa forma, as condições de produção se referem a todo contexto a partir do qual vai surgindo o discurso.

Interessante observar que Foucault (1996) caracteriza a noção de formação discursiva pontuando que os discursos não são isolados, mas existem como uma dispersão - não estão bem delimitados cada um deles com sua autonomia como se pensava na primeira fase da AD. A dispersão aqui é concebida como diversas formações discursivas concorrentes nos diversos campos e que elas se caracterizam por um processo de delimitações recíproco. Exemplo disso é a religião, em que se observa diversas formações discursivas dentro desse campo, tais como muçulmana, cristã, espírita, de matriz africanas e suas ideias passam por uma delimitação recíproca, se aproximam em alguns pontos e se distanciam em outros. Mussalim (2004, p. 119) pontua que "O espaço de uma FD é atravessado pelo pré-construído, ou seja, por discursos que vieram de outro lugar (de uma construção anterior e exterior) e que são incorporados por ela numa relação de confronto e aliança".

Também é possível notar que a noção de formação discursiva (autônoma) é deixada de lado e preocupa-se com o interdiscurso, isto é, aquele ponto de intersecção, de comunicação, ponto em que os discursos estão dialogando. Toda análise desta fase procura trabalhar cada discurso no diálogo que ele mantém com os discursos concorrentes, com as formações discursivas. Ou seja, a análise procura caracterizar um discurso em relação a outro e não tomando-o de maneira isolada e é nessas relações que se percebe o antagonismo e as semelhanças.

Pêcheux também trata da concepção de interdiscurso. Essa noção, concebe que os discursos que atravessam uma formação discursiva não se constituem de maneira autônoma, mas se constituem de modo regulado 'no interior de um interdiscurso'. 
Por isso, o objeto desta fase é o interdiscurso e a relação interdiscursiva é que estruturará a identidade das formações discursivas analisadas.

Para Gregolin (2005), o interdiscurso é o lugar em que se constituem os objetos que o enunciador se apropria para trazê-los ao seu discurso e a relação estabelecida entre o intra-discurso e o interdiscurso. A noção de interdiscurso, tomado como relação de um discurso com outros é importante para que se chegue à compreensão e que os discursos são gerados por meio do confronto, da interação, que estabelecem entre si. Orlandi (1991, p. 89) afirma que "o interdiscurso é o conjunto dizível, histórica e linguisticamente definido". Nesse sentido, este dizível é aquilo que é enunciável e se apoia no já-dito. Por isso, acontece em um lugar/espaço exterior à língua e ao sujeito.

\section{ANÁLISE E ALGUNS APONTAMENTOS}

Para realizar as discussões propostas neste artigo, coletou-se o corpus com base e buscou-se alguns dos chargistas mais conhecidos que divulgam seus trabalhos em jornais e revistas de grande circulação impressa e on-line. Mas, além disso, buscou-se charges que relacionavam o momento de pandemia com COVID-19 (acontecimento) com histórias literárias infantis e infantojuvenis clássicas. Foi possível coletar 13 charges. Destas, selecionamos 4 para análise, levando em conta o espaço para se realizar as análises neste artigo. A pesquisa foi realizada na internet por meio de buscas no navegador Google e sites de chargistas renomados, com as palavras-chave 'charge sobre coronavírus', 'Charges de Duke sobre pandemia', 'Charges de Jota A sobre pandemia' e 'Charges de Amarildo sobre pandemia'. Também buscamos jornais e revistas on-line com os acontecimentos a que as charges faziam referência.

Desde o início da Pandemia provocada pelo coronavírus, em especial, no Brasil, em Março de 2020, o presidente brasileiro e muitos daqueles que compartilham de suas ideias produziram uma série de discursos de toda sorte ironizando a gravidade da situação, defendendo a massificação de medicamentos não aprovados pela ciência e negando a eficácia da vacinação; bem como negando os efeitos positivos do isolamento social, determinado por prefeitos e governadores, por meio de Decretos Municipais e Estaduais. 


\section{Imagem 1 - Charge 'Os três porquinhos'}

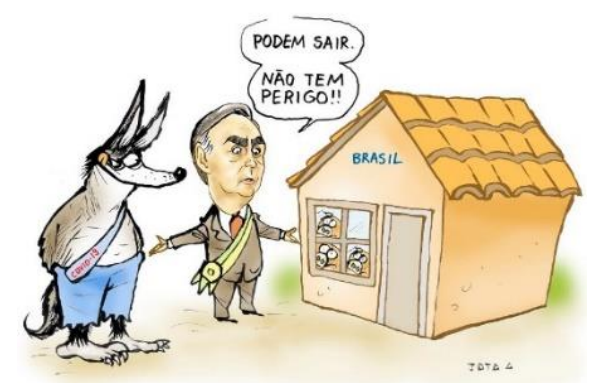

Fonte: Portaldodia.com. Disponível em: https://www.portalodia.com/blogs/jotaa/confira-a-charge-de-jotaa-publicada-na-edicao-desta-quinta-do-jornal-o-dia-375502.html. Data: 26/03/2020

A imagem da charge, juntamente com o texto verbal, é essencial para a compreensão e a produção do humor na charge acima, de Jota A. Nela, é possível vislumbrar a caricatura de Jair Messias Bolsonaro, o presidente da república brasileira, juntamente com um lobo. Ambos usam uma faixa, na do presidente, representa a faixa da presidência e a do lobo escrita COVID-19. Também, é possível ver uma casa escrita 'Brasil', com imagens na janela, que fazem alusão aos três porquinhos. Interessante que observamos na charge o cruzamento de diferentes discursos, tal como o literário: da história infantojuvenil "Os três porquinhos"; o discurso político (advindo do chefe do poder executivo brasileiro); o discurso da saúde e dos órgãos, como a OMS que instituíram protocolos, como o isolamento social e a quarentena.

Os discursos que fazem parte da charge, surgem por meio da interdiscursividade, que se liga aos discursos que circulam por meio de jornais impressos e on-line e mídias televisivas, do representante do poder executivo brasileiro indo na contramão das orientações dos órgãos de saúde internacionais e nacionais, de isolamento social e quarentena.

Importa retomar as afirmações de Michel Pêcheux, quando afirma que o discurso é sempre pronunciado a partir das condições de produção dadas, e caracteriza-se por ligações de sentido nas quais ele - discurso- é produzido. Os discursos presentes na charge fazem referência a outros discursos, nos quais se apoiam e já preexistem.

A charge de Jota A, portanto, ao ser produzida, chama a atenção e critica um fato: o de que o presidente Jair Messias Bolsonaro estava dando pouca relevância à COVID19 , realizando atos que vão contra os protocolos estabelecidos pelas autoridades em saúde e pedindo a flexibilização. Nesta charge, observa-se que a temática isolamento social é discutida e que as condições de produção são diferentes daquela em que se observa a 
mesma temática, em entrevistas à jornais e em veículos de comunicação impresso e online.

O acontecimento discursivo mais marcante ao qual a charge se relaciona é a crítica de Bolsonaro ao isolamento social, feita no dia 24 de março, quando completava quase 1 mês do primeiro caso de COVID-19 noticiado no Brasil. Inúmeros governadores optaram por manter o isolamento social, principal medida para evitar o ritmo das infecções. Neste dia, o Brasil chegava à 2,5 mil infectados e 60 mortes. $\mathrm{O}$ primeiro óbito confirmado pelo coronavirus havia ocorrido em 17 de março e em 25 de março, Rio de Janeiro e São Paulo haviam adotado a restrição de serviços e de circulação de pessoas a exemplo de outros países que também adotaram o isolamento social. Além de São Paulo e Rio de Janeiro, outros Estados, como Goiás e Mato Grosso do Sul, também decretaram isolamento e manutenção apenas de serviços essenciais.

Em 24 de março, em pronunciamento, Jair Messias Bolsonaro afirma que a rotina do país deveria voltar à realidade e que a imprensa tinha espalhado o pânico em torno da COVID-19. Além disso, critica o fechamento das escolas e afirma que crise passará. Neste pronunciamento, chamou novamente o novo coronavírus de 'gripezinha', o que havia feito dias antes, quando, no dia 20 de março, após terminar uma entrevista coletiva, se referiu à doença como uma 'gripezinha', conforme transcrição: “Depois da facada, não vai ser gripezinha que vai me derrubar não, tá ok?”.

O pronunciamento do dia 24 de março foi em razão do ministro do Supremo Tribunal Federal, Marco Aurélio Mello, ter decidido, que a Medida Provisória, editada pelo Presidente determinando que apenas o governo federal poderia restringir a circulação entre municípios e estados. Esta medida mudava trechos, à época, de outra medida provisória já editada em fevereiro e que tratava de procedimentos para enfrentar a COVID-19, tal como a quarentena e a proibição do fluxo de pessoas. O texto da medida provisória 'nova', fonte de decisão do STF, afirmava que a restrição excepcional e temporariamente seria realizada de acordo com recomendações técnicas e fundamentada na Agência Nacional de Vigilância Sanitária - Anvisa e incluía tráfego em rodovias, portos e aeroportos para entrada e saída do país e 'locomoção interestadual e intermunicipal', parte que não se encontrava na Medida Provisória de fevereiro. Esta nova Medida Provisória foi uma retaliação às tomadas de decisão por parte dos governadores, em especial, o do Rio de Janeiro, Wilson Witzel e o de São Paulo, João Dória, que fecharam as divisas do Estado. Além disso, a nova Medida Provisória (MP 926), 
estabelecia que as medidas adotadas seriam apenas do governo federal e haveria a garantia do funcionamento de 33 serviços e atividades essenciais. Sendo assim, Marco Aurélio, ministro do Supremo, decidiu que: "Não se pode ver transgressão a preceito da Constituição Federal. As providências não afastam atos a serem praticados por Estado, o Distrito Federal e Município considerada a competência concorrente na forma do artigo 23, inciso II, da Lei Maior" (DECISÃO STF. 23/03/2020). Acatando o pedido do PDT em partes.

Dia 25 de março, após pronunciamento, o Presidente repete ataques aos governadores e critica isolamento e quarentena, chamando de crime as ações de, segundo ele, 'alguns poucos' prefeitos e governadores, em entrevista a jornalistas na saída da residência oficial do Palácio da Alvorada. Afirmou ainda conversar com ministro da Saúde sobre o isolamento vertical, menos rigoroso. Se justificou afirmando que o isolamento social iria criar uma crise econômica, gerar conflitos sociais e abalos à democracia. Disse ainda, que esperava que o vírus não matasse ninguém, mas que outros vírus mataram e não causaram 'essa comoção toda'.

No dia 26 de março, João Dória leu proposta de governadores para combater o coronavírus e 26 dos 27 governadores assinaram a proposta. Nesse pronunciamento, João Dória lê a introdução e as solicitações feitas pelos governadores. Informa, ainda, que os governadores continuariam se reunindo para padronizar as tomadas de decisão frente à COVID-19. Neste período também, o governo anunciava a campanha “O Brasil não pode parar", com vídeos em que defende a flexibilização do isolamento social e a movimentação da economia.

Caso não se tivesse conhecimento das condições de produção e do acontecimento que desencadeou a elaboração da charge, possivelmente, não se conseguiria atribuir o sentido emanado dali. O interdiscurso, neste caso, é estabelecido com a estória de 'Os três porquinhos'. Tendo o conhecimento desta, o interlocutor consegue atribuir novos sentidos à charge. Assim, o contato com outros discursos permite que nós possamos reconhecer que o discurso da charge partiu da estória literária.

O lobo aparece representando metaforicamente a COVID-19 e os perigos que a doença oferece, a casa dos três porquinhos, representa o país - Brasil e o a fala do chefe do executivo afirma: "Podem sair! Não tem perigo". Quando, na realidade, sabemos que, ao sair da casa, obviamente, os três porquinhos estão em perigo. Por fỉm, podemos afirmar que o conhecimento da estória de 'Os três porquinhos', que é trazido pela 
memória discursiva, e da situação da COVID-19 e do discurso presidencial sobre o isolamento social e a movimentação da economia, não seria possível atribuir sentido à charge. Orlandi (2012) pontua que as condições de produção implicam tanto o contexto que é imediato à enunciação, quanto o contexto sócio-histórico e ideológico.

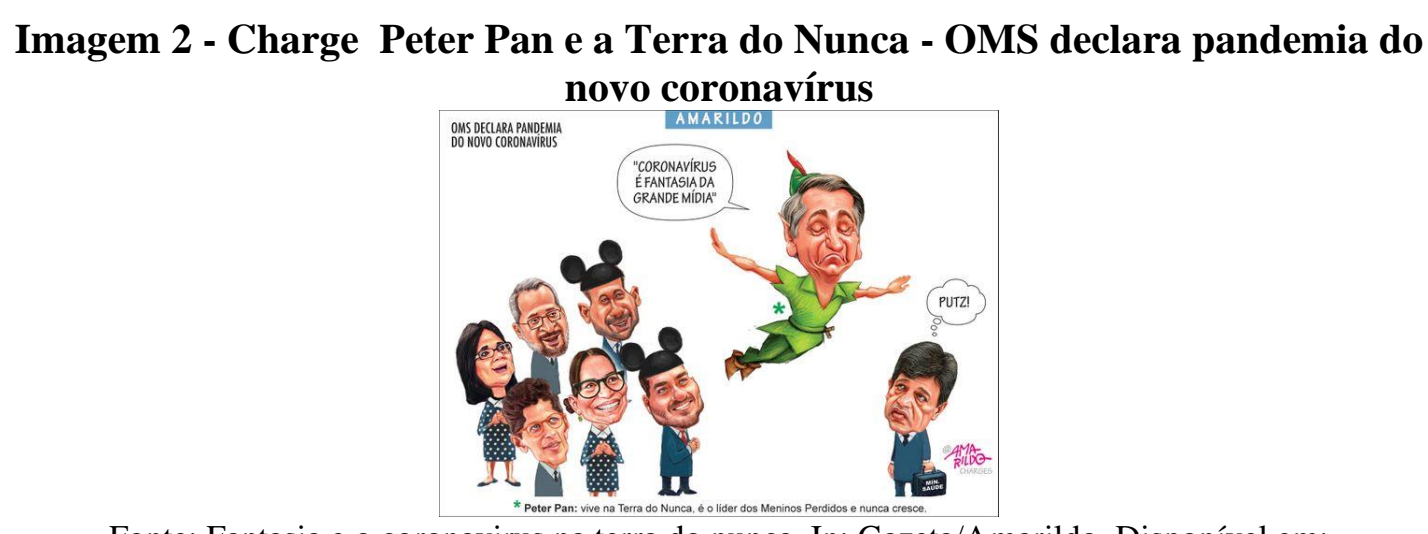

Fonte: Fantasia e o coronavirus na terra do nunca. In: Gazeta/Amarildo. Disponível em: https://www.agazeta.com.br/charge/charge-do-amarildo-fantasia-e-o-coronavirus-na-terra-do-nunca0320. Data: $12 / 03 / 2020$

Em evento em Miami, com a comunidade brasileira, o Presidente Jair Bolsonaro minimizou a pandemia anunciada em 11 de março pela Organização Mundial de Saúde, OMS, mesmo que naquela ocasião o vírus SARS-CoV2, já tivesse causado mais de 3.000 no mundo e estivesse presente em inúmeros países. No Brasil, havia 25 casos diagnosticados. O presidente se posicionou da seguinte forma: "Tem a questão do coronavirus também que, no meu entender está superdimensionado, o poder destruidor deste vírus. Então, talvez esteja sendo potencializado até por questão econômica, mas acredito que o Brasil não é que vai dar certo, já deu certo". Além disso, em 10 de março, um dia após os mercados financeiros em todo o mundo registrarem perdas históricas, o presidente também se pronunciou afirmando sobre a COVID-19 que "Obviamente temos no momento uma crise, uma pequena crise. No meu entender, muito mais fantasia a questão do coronavírus, que não é tudo isso que a grande mídia propala ou propaga pelo mundo todo".

A charge se intitula "OMS declara pandemia do novo coronavírus" o que faz com que se retome a declaração da OMS do dia anterior sobre a pandemia, em que o órgão internacional de Saúde tratou da situação do novo coronavírus e o quanto ele já havia se expandido em inúmeros países e também faz retomar a fala do Presidente ao dizer que a questão do coronavírus era fantasia e que não era tudo aquilo que a mídia estava divulgando no mundo todo. Isto nos remete à ideia de que Peter Pan era um garoto que 
vivia no mundo da fantasia. Isso porque a charge apresenta interdiscurso entre a estória de Peter Pan e o discurso do Presidente Jair Bolsonaro (política). Nesse sentido, o interlocutor percebe a relação com outros discurso o que o possibilita de reconhecer que o discurso apresentado tem base na estória de Peter Pan. A charge atribui um novo significado ou possibilita ao interlocutor que o faça. Isso porque a charge nos faz ou nos direciona ao contexto vivenciado no Brasil na esfera dos discurso advindos do chefe do Executivo, na política e o discurso científico, trazido pela OMS sobre a situação de pandemia. Retomando Orlandi (2012), as condições de produção da charge incluem esse contexto imediato de enunciação e também o contexto sócio-histórico e ideológico. Importante ratificar que para atribuir sentido à charge necessitamos ter o conhecimento acionado pela memória discursiva sobre a estória literária e os discursos políticos do Chefe do Poder Executivo, Jair Bolsonaro.

\section{Imagem 3 - Charge "Branca de neve e a cloroquina"}

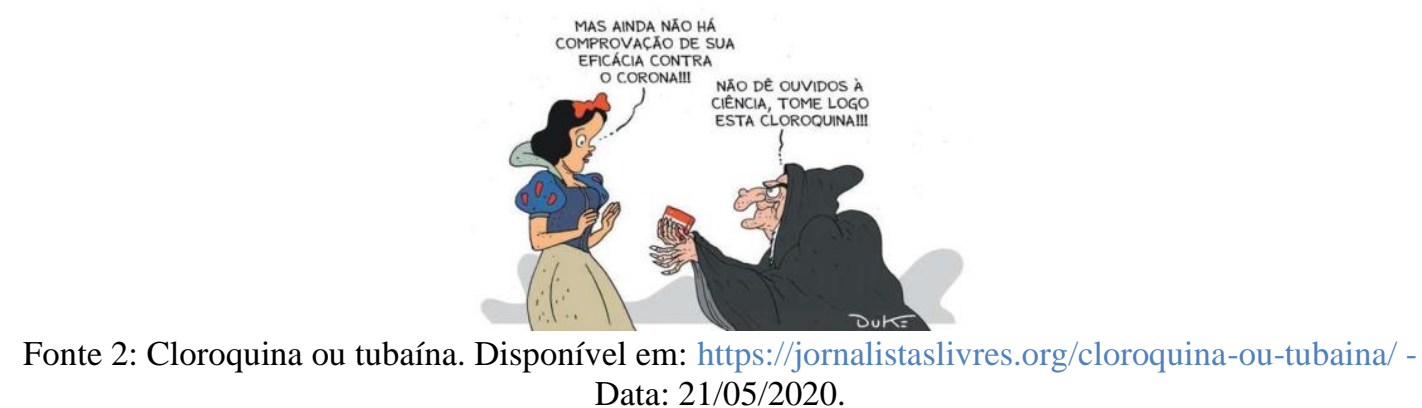
Data: $21 / 05 / 2020$.

No dia 19 de maio de 2020, o presidente Jair Bolsonaro, em live que o ministro interino, general Eduardo Pazuello, assinaria novo protocolo para permitir o uso da cloroquina em pacientes em estágio inicial de contágio por coronavírus. Isso porque o protocolo anterior do Ministério da Saúde permitia o uso apenas em pacientes em estágio grave. Ainda, o presidente afirmou que isso daria liberdade para o paciente decidir se quer ou não quer usar. Ao tratar disso colocou: "O que é a democracia? Você não quer? Você não faz. Você não é obrigado a tomar cloroquina. Quem é de direita toma cloroquina. Quem é de esquerda toma Tubaína", em referência a uma marca de refrigerante. Também fez uma crítica ao governador pernambucano, Paulo Câmara, que na época, havia sido diagnosticado com a COVID-19, nos seguintes termos: "Eu acho que quem falou que era veneno, não pode tomar. O governador pode tomar a cloroquina. Pode ser que não precise. Mas, no seu lugar, eu tomaria". Na mesma live, o presidente afirmou que talvez a cloroquina seja reconhecida apenas como placebo no combate à doença, mas pode 
também ser descoberta a sua eficácia na cura. Nesse sentido, não há comprovações científicas da eficácia da cloroquina e algumas pesquisas norte-americanas, divulgadas na mídia, haviam mostrado que o uso pode causar danos à saúde.

Essa fala do presidente faz retomar, também, a fala do dia 21 de março, quando se reuniu com o ministro da Defesa. Neste dia, o presidente Jair Bolsonaro afirmou que decidiu, em reunião com o ministro da Defesa, que o Laboratório químico e farmacêutico do Exército ampliaria a produção de cloroquina, testada em pacientes com coronavírus em tratamento, mesmo que a Agência Nacional de Vigilância Sanitária (Anvisa) e outros órgãos nacionais e internacionais ligados à saúde tenham informado que não há recomendação de sua utilização no combate à COVID-19, ou como prevenção. Isto porque, segundo esses órgãos, não havia comprovação em relação ao tratamento com cloroquina ou hidroxicloroquina, contra a COVID-19. Na ocasião, o presidente informou que o hospital Albert Einstein iniciaria protocolos de pesquisa para verificar a eficácia em pacientes e no tuíte, colocou o título 'Hospital Albert Einstein e a possível cura dos pacientes com o COVID-19”. Nesta entrevista à CNN Brasil, Bolsonaro afirmou que estava confiante no Reuquinol, medicamento que tem como princípio ativo a hidroxicloroquima e que esta seria eficiente para evitar um contágio mais rápido da doença no Brasil.

Na charge, aparece a Branca de Neve e a bruxa em um momento clássico da história 'Branca de Neve e os sete anões', quando é oferecido à princesa uma maçã envenenada. Porém, na charge a bruxa traz a caixa de cloroquina. Branca de Neve fala: mas ainda não há comprovação de sua eficácia contra o coronavírus; e, a bruxa responde: - Não dê ouvidos à ciência, tome logo esta cloroquina. As falas levam a concluir que a cloroquina é tida como veneno. O discurso da charge faz com que retomemos o conhecimento sobre a estória da Branca de Neve e os sete anões e os discursos do Presidente Jair Bolsonaro. Aqui o interdiscurso na charge se apresenta entre a estória da Branca de Neve e os sete anões e a fala de Jair Bolsonaro, quando trata de remédios que não têm eficácia científica comprovada para o tratamento da COVID-19. Isto leva o interlocutor a compreender, é claro, quando ele conhece a estória (ou ambas), o quanto é importante pensar a estória para compreender. 


\section{Imagem 4 - Charge "Os Duendes"}

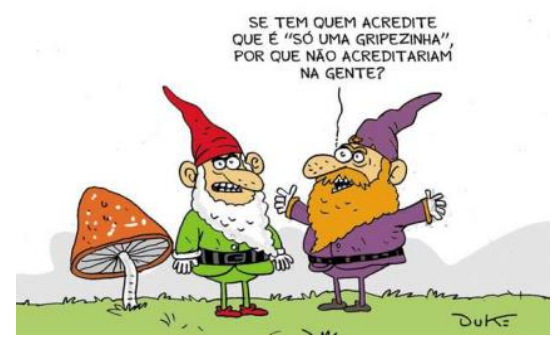

Fonte: Charge do Cartunista Duke. Jornal on-line: O tempo. Data: 18/06/2020

A charge de Duke faz com que se retome a fala do Presidente Jair Bolsonaro no dia 24 de março, quando o país registrava mais de 10 mortes pelo vírus. Neste pronunciamento à televisão, ele criticou o fechamento do comércio e das escolas e comparou a contaminação por coronavírus como uma 'gripezinha', um 'resfriadinho' e afirmou: "No meu caso particular, pelo meu histórico de atleta, caso fosse contaminado pelo vírus, não precisaria me preocupar, nada sentiria ou seria, quando muito, acometido de uma gripezinha ou resfriadinho, como bem disse aquele conhecido médico daquela conhecida televisão".

No ditado popular, quando alguma pessoa fala algo fora da 'realidade' as pessoas costumam dizer 'você agora acredita em duendes?' Quer dizer, os anões e duendes são seres fantasiosos, fazem parte do imaginário, das histórias literárias. Sendo assim, não se referem ao que acontece no mundo real. Na charge, um duende questiona para o outro: Se tem quem acredite que "é só uma gripezinha", por que não acreditariam na gente? Tal charge nos remete à inúmeras histórias em que duendes aparecem e que coletivamente, não se acredita em duendes, por serem personagens de histórias fantasiosas da literatura infantil e infantojuvenil. Justamente por esta razão, a charge, retomando na memória, compreendemos que é necessário ter um aval para o dono assinar.

A charge atribui um novo significado ou possibilita ao interlocutor que o faça. Isso porque a charge nos faz ou nos direciona ao contexto vivenciado no Brasil na esfera dos discurso advindos do chefe do Executivo, na política e o discurso científico, trazido pela OMS sobre a situação de pandemia. Retomando Orlandi (2012), as condições de produção da charge incluem esse contexto imediato de enunciação e também o contexto sócio-histórico e ideológico. Importante ratificar que para atribuir sentido à charge necessitamos ter o conhecimento acionado pela memória discursiva sobre a estória literária e os discursos políticos do Chefe do Poder Executivo, Jair Bolsonaro. 


\section{DIÁLOGOS FINAIS}

As charges nos possibilitam perceber os discursos que se entrecruzam para que o leitor possa construir os sentidos. Válido dizer que sem o conhecimento dos livros literários aos quais as charges - cada uma delas - faz referências, jamais conseguiríamos construir sentidos.

O texto aqui teve como principal intenção dialogar sobre os conceitos de discurso, interdiscurso, formação discursiva e outros que permitem compreender melhor como o sentido é construído nos textos chargísticos. Isso nos faz retomar que as charges selecionadas mostram o quanto esses textos permitem ter um olhar atento ao sujeito, à língua e à história, que são elementos que além de atualizarem os enunciados, possibilitam a construção de sentidos. Nesse viés, importante observar que a análise do discurso deve dar os subsídios necessários para que a análise fuja da mera especulação do texto e adentre aos percalços discursivos que permitem observar o entrecruzamento entre os enunciados historicamente situados.

É essa ligação interdisursiva que notamos entre os enunciados que são cotidianamente veiculados na sociedade e que contribuem para o humor existente na charge. Esta discursividade é visto como uma dispersão de enunciados e o interdiscurso, ainda, proporciona ao sujeito retomar várias evidências que são aceitáveis socialmente e são observadas, o que permite trazer novos significados aos textos, novos sentidos ao discurso já dito.

O discurso chargistico é, como pudemos confirmar, atravessado, cindido, entrecortado por outros inúmeros discursos veiculados socialmente, e que é possível reconhecer. Ainda, as marcas de heterogeneidade discursiva nos textos analisados permitem retomar a relação com a linguagem e a memória, o que necessita de retomada e interpretação de alguns acontecimentos ligados à diferentes formações discursivas, em que os enunciados dialogam a fim de constituírem os efeitos de sentidos no texto.

Importante, ainda, observar que a materialidade discursiva possibilita a relação entre memória discursiva e o interdiscurso; a primeira como uma representação da existência histórica dos enunciados inscritos em uma dada FD; e, o segundo, como um conjunto de enunciados ditos e esquecidos. E, ratificar a importância das condições de produção, pois esta determina a constituição do sujeito e do sentido de seu discurso. E, o sentido não é pré-existente, mas pode se tornar outro quando se inscreve na formação ideológica e o sujeito que enuncia e inscreve 'em uma ou outra formação ideológica'. 
Além disso, o sentido só é produzido, no caso das charges, porque uma memória é retomada.

\section{REFERÊNCIAS}

BRANDÃO, Helena H. Nagamine. Introdução à Análise do Discurso. Campinas, S. R: Editora da UN1CAMP, 2004.

FOUCAULT, Michel. A arqueologia do saber. Rio de Janeiro: Forense Universitária, 1996.

FOUCAULT, Michel. A arqueologia do saber. Rio de Janeiro: Forense Universitária, 2002.

FOUCAULT, Michel. A ordem do discurso. São Paulo: Loyola, 2015.

GREGOLIN, Maria do Rosário. Formação discursiva, redes de memória e trajetos sociais de sentido: mídia e produção de identidades. Texto apresentado no II Seminário de Análise do Discurso (SEAD), na UFRGS, Porto Alegre, 2005. Uma versão mais sintética foi publicada em CDROM, nas atas do II SEAD. Disponível em: https://moodle.ufsc.br/pluginfile.php/1867818/mod_resource/content/1/Gregolin_Forma cao_discursiva_redes_de_memoria.pdf. Acesso em: outubro de 2020.

MUSSALIM, F. Análise do Discurso. In: MUSSALIM, F. \& BENTES, A.C. (Org.) Introdução à linguística - Domínios e Fonteiras. São Paulo: Cortez, 2004. Vol 2

ORLANDI, Eni Puccinelli. Análise de Discurso: princípios e procedimentos. São Paulo: Pontes, 2012.

ORLANDI, E. Michel de Pêcheux e a Análise do Discurso. Revista Estudos de Linguagem, Vitória da Conquista, $\mathrm{n}^{\circ}$ 1, p. 9 -13, 2005.

PÊCHEUX, Michel. Papel da Memória. In: ACHARD, P. Papel da Memória. Campinas, Pontes, 1983.

PÊCHEUX, M. O discurso: estrutura ou acontecimento. Tradução de Eni Pulcinelli Orlandi. 4. ed. Campinas: Pontes, 2006.

PILLA, Armando; DE QUADROS, Cyntia. Charge: uma leitura orientada pela análise do discurso de linha francesa. Linguagens. Revista de Letras, Artes e Comunicação. Blumenau, v. 3, n. 3, p. 226-239, set./dez. 2009. Disponível em: https://proxy.furb.br/ojs/index.php/linguagens/article/view/1497. Acesso em: 22-de novembro, 2021.

POSSENTI, S. Análise do discurso e acontecimento: breve análise de um caso. In: NAVARRO, Pedro (org.) Estudos do texto e do discurso: mapeando conceitos e métodos. São Carlos: Claraluz, 2006.

SARGENTINI, V. M. O. Os estudos do discurso e nossas heranças: Bakhtin, Pêcheux e Foucault. Revista Estudos Linguísticos XXXV, p. 181-190, 2006 
SILVA, Telma Cristina Gomes. O interdiscurso no gênero charge: um estudo do discurso humorístico sob a perspectiva da Análise do Discurso francesa. Domínios de Linguagem. Revista Eletrônica de Linguística. Volume 6, n. 1 - 1 semestre, 2012. Disponível em: https://seer.ufu.br/index.php/dominiosdelinguagem/article/view/14742. Acesso em: 16 de dezembro de 2021.

Recebido em: 20/01/2022

Aprovado em: 21/02/2022

Publicado em: 25/02/2022 